\title{
Error Analysis: Sources of L2 Learners’ Errors
}

\author{
Pooneh Heydari \\ Department of Foreign Languages, Shiraz Branch, Islamic Azad University, Shiraz, Iran \\ Email: pooneh.heydari@yahoo.com \\ Mohammad S. Bagheri \\ Department of Foreign Languages, Shiraz Branch, Islamic Azad University, Shiraz, Iran
}

\begin{abstract}
Many scholars in the field of EA have stressed the significance of second language learners' errors. Corder (1967), for instance, in his influential article, remarks that "they are significant in three different ways. First, to the teacher, in that they show how far towards the goal the learner has progressed. Second, they provide to the researcher evidence of how a language is acquired, what strategies the learner is employing in his learning of a language. Thirdly, they are indisputable to the learner himself because we can regard the making of errors as a device the learner uses in order to learn" (p. 161). The present paper mostly illustrates fundamental background studies done in the field of Error Analysis. There is the hope that the paper helps EFL teachers and educators to become familiar with the most frequent errors committed by EFL learners leading them to make more objective decisions about how to go about adopting appropriate teaching strategies to help EFL students learn better.
\end{abstract}

Index Terms — error analysis, error taxonomies, interlingual errors, intralingual errors

\section{INTRODUCTION}

In recent years, there has been a growing research interest in the analysis of errors adults make while learning a second language. The study and analysis of the errors made by second language learners (i.e. Error Analysis or EA), either in their speech or writing or both has been brought under consideration by many educators, EFL teachers, linguists, and researchers throughout the world. In fact, learners' errors have been the subject of controversy for a long time.

Generally, as Keshavarz (1999, p. 11) stated, "there have been two major approaches to the study of learners' errors, namely Contrastive Analysis and Error Analysis." He further discussed that, "Error Analysis emerged on account of the shortcomings of Contrastive Analysis which was the favored way of describing learners' language in the 1950s and 1960s" (p. 42).

The process involved in CA is the comparison of learners' mother tongue and the target language. Based on the similarities or differences between two languages, predictions were made on errors that learners would be likely or disposed to make as a result (Kim, 2001). CA arose from a critical view of the audio-lingual method, pointing out that only with scientific and detailed description of L2 can language teaching be successful (Fries, 1949).However, as Kim (2001) explained, by early 1970s, CA lost its favor because of the inaccurate or uninformative predictions of learner errors; errors did not occur where predicted, but instead errors showed up where CA had not predicted. More serious criticism was raised on account of its adopted views from structuralism in linguistics and behaviorism in psychology. Being questioned about the reliability of the CA research, it yielded to Error Analysis in 1970.

Unlike CA which tries to describe differences and similarities of L1 and L2, James (1998 cited in Kim, 2001) stated that, EA attempts to describe learners' interlanguage (i.e. learners' version of the target language) independently and objectively. He believed that the most distinct feature of EA is that the mother tongue is not supposed to be mentioned for comparison. Hence, the studies in EA have for the most part dealt with linguistic aspects of learners' errors. In fact, identifying and describing the origin of the learners' errors is now an activity that has received much attention during the last three decades. Such an analysis may lead one to understand the types of significant cohesive errors associated and the origin of such errors.

\section{ERROR ANALYSIS}

Writing is a complex process even in the first language. Undoubtedly, it is more complicated to write in a foreign language. Consequently, lots of researchers have intended to identify the common errors EFL students make in writing the second language. Of course, a better understanding of the errors and the origin of such errors in the process of EFL writing will help teachers know students' difficulties in learning that language. Moreover, it will aid in the adoption of appropriate teaching strategies to help EFL students learn better.

Therefore, EA can be considered as a fundamental tool in language teaching in order to reorganize teacher's point of view and readdress his/her methodology for fixing and fulfilling the students' gaps (Londono Vasquez, 2007). In other words, as Corder (1967) defined, EA is a procedure used by both researchers and teachers which involves collecting 
samples of learner language, identifying the errors in the sample, describing these errors, classifying them according to their nature and causes, and evaluating their seriousness. The purpose of Error Analysis is, in fact, to find " what the learner knows and does not know" and to " ultimately enable the teacher to supply him not just with the information that his hypothesis is wrong, but also, importantly, with the right sort of information or data for him to form a more adequate concept of a rule in the target language" (Corder, 1974, p. 170).

Consequently, the review of the literature that follows addresses itself to the sources of errors rather than the most frequent EFL learners' errors reported in various studies per se. At first, for this review of the literature, it is necessary to study known and popular error taxonomies and classifications.

\section{ERROR TAXONOMIES}

Perhaps, one of the first and most important studies conducted in the field of Error Analysis was the one done by Richards (1971). His study involved learners from different language background (Japanese, Chinese, Burmese, French, Czech, Polish, Tagalog, Maori, Maltese, and Indian and West African Languages) and showed the different types of errors relating to production and distribution of verb groups, prepositions, articles, and the use of questions. Based on this, he distinguished three sources of errors:

1. Interference errors: errors resulting from the use of elements from one language while speaking/writing another,

2. Intralingual errors: errors reflecting general characteristics of the rule learning such as faulty generalization, incomplete application of rules and failure to learn conditions under which rules apply, and

3. Developmental errors: errors occurring when learners attempt to build up hypothesis about the target language on the basis of limited experiences.

According to Richards (1971), intralingual errors are also subdivided to the following categories:

1. Overgeneralization errors: the learner creates a deviant structure on the basis of other structures in the target language (e.g. "He can sings" where English allows "He can sing" and "He sings").

2. Ignorance of rule restrictions: the learner applies rules to context where they are not applicable (e.g. He made me to go rest" through extension of the pattern "He asked/wanted me to go").

3. Incomplete application of rules: the learner fails to use a fully developed structure (e.g. "You like to sing?" in place of "Do you like to sing?")

4. False hypothesis: the learners do not fully understand a distinction in the target language (e.g. the use of "was" as a marker of past tense in "One day it was happened").

However, as Schacheter and Celce-Murcia (1977) pointed out, the distinction between intralingual and developmental errors is rather fuzzy in their term. As a result, Richards (1974) classified errors, according to their causes, into two categories later on. The two categories are as follows:

1. Interlingual errors: these errors are caused by mother tongue interference.

2. Intralingual and developmental errors: this kind of errors occurs during the learning process of the second language at a stage when the learners have not really acquired the knowledge. In addition, errors are also caused by the difficulty or the problem of language itself.

Elsewhere, some experts believed that the distinction between intralingual and interlingual errors is not always clearcut as it may sound. They also claimed that it is obviously more difficult to identify different types of intralingual errors that Richards (1971) described. In order to deal with this problem, Dulay and Burt (1974) classified learners' errors into three broad categories:

1. Developmental errors: errors that are similar to L1 acquisition

2. Interference errors: errors that reflect the structure of the L1

3. Unique errors: errors that are neither developmental nor interference

Stenson (1974 cited in Karra, 2006) proposed another category, that of induced errors, which resulted from incorrect instruction of the language.

Brown (1980 cited in Hasyim, 2002) further classified sources of errors into the following categories:

1. Interference transfer: that is the negative influence of the mother tongue of learner,

2. Intralingual transfer: that is the negative transfer of items within the target language. In other words, the incorrect generalization of the rules within the target language,

3. Context of learning: this overlaps both types of transfer. For example, the classroom with the teacher and its materials in the case of school learning or the social situation in the case of untutored second language learning. In a classroom context, the teacher or the textbook can lead the learner to make wrong generalization about the language, and

4. Communication strategies: it is obvious that communication strategy is the conscious employment of verbal mechanisms for communicating an idea when linguistic forms are not available to the learner for some reasons.

There are five main communication strategies, namely:

1. Avoidance,

2. Prefabricated patterns,

3. Cognitive and personality style,

4. Appeal to authority, and 
5. Language switch (Brown, 1980 cited in Hasyim, 2002).

Later, James (1998), in his study, showed the different types of learners' errors relating to omission, overinclusion, misselection (use wrong words not wrong forms), misordering, blends (blending arises when two alternative grammatical forms are combined to produce an ungrammatical blend.)Based on this, he stated that there are four causes of errors.

1. Interlingual errors (Mother-tongue influence): these kinds of errors are influenced by the native languages which interfere with target language learning,

2. Intralingual errors: these types of errors are caused by the target language itself like: false analogy, misanalysis (learners form a wrong hypothesis), incomplete rule application (this is the converse of overgeneralization or one might call it undergeneralization as the learners do not use all the rules), Exploiting redundancy (this error occurs by carrying considerable redundancy. This is shown throughout the system in the form of unnecessary morphology and double signaling), Overlooking co-occurrence restrictions (this error is caused by overlooking the exceptional rules), Hypercorrection or monitor overuse (this results from the learners' over cautious and strict observance of the rules), Overgeneralization or system-simplification (this error is caused by the misuse of words or grammatical rules),

3. Communication strategy-based errors which are subdivided into the holistic strategies or approximation and analytic strategies or circumlocution, and

4. Induced Errors:these errors are the result of being misled by the way in which the teachers give definitions, examples, explanations and arrange practice opportunities. In other words, the errors are caused mostly by the teaching and learning process as follows: Materials-induced errors, Teacher-talk induced errors, Exercise-based induced errors, Errors induced by pedagogical priorities, Look-up errors.

In fact, most researchers have been contented with a general distinction between transfer errors [Richards' (1971) category 1] and intralingual errors [combination of Richards' (1971) 2 and 3]. Besides, sub-categorization of intralingual errors is not unproblematic but should be credited for providing operational procedures for establishing which errors are intralingual (Ellis, 1994).

Finally, by using Richards' distinction of learners' errors — interlingual and intralingual — as a basis of analysis, different researches done in this respect will be reviewed in the following two sections.

\section{STUdies Done On InTERLINGUAL CAUSES}

Indeed, efforts have been made to identify and describe learners' errors. Among them, various researchers have concentrated on those errors which demonstrate the influence of one's native language to second language acquisition.

To investigate the relationship between students' L1 and EFL writing, Ying (1987) examined 120 Taiwanese EFL students' compositions and sorted errors on the basis of three criteria of overgeneralization, simplification, and language transfer. A total of 1250 errors were detected in the 120 compositions, among which $78.9 \%$ of the errors were a result of language transfer, $13.6 \%$ of the errors were overgeneralization of the target language, and $7.5 \%$ were forms of simplification.

In addition, Kim (1989 cited in Lee, 2001) conducted Error Analysis with two-hundred $10^{\text {th }}$ grade Korean EFL learners using their English translation of Korean sentences. She identified 1122 errors in which transfer errors resulting from L1 structure were higher (24\%) than overgeneralization errors (23\%). Furthermore, she identified the 1122 detected errors in terms of six domains and subdivided them into 22 linguistic categories. Her findings revealed that errors in articles were most common (354) and that there were only 8 errors in word order and 2 in voice.

Likewise, Jiang (1995) analyzed Taiwanese EFL learners' errors in English prepositions and found that a great number of errors derived from language transfer. The researcher stated that compared to English speakers, Mandarin speakers use fewer prepositions for more concepts, therefore increasing difficulties in learning English prepositions.

In addition, some researchers employed Error Analysis to examine the error types in Taiwanese EFL students' English writings. For example, Horney (1998 cited in Chen, 2006) investigated compositions written by 80 Taiwanese EFL students. The results revealed that errors in the use of articles had the highest error percentage (11\%). Both errors in the use of prepositions and errors in the use of verbs had the same error rate of $9 \%$ and were considered the second highest error percentage. By contrasting Mandarin and English, the researcher confirmed that L1 related errors were the largest proportion of the total errors.

Along the same lines, Liu, Sung, and Chien (1998) also concluded that the less English proficiency learners possess, the more L1 interference was found in their English writings. In the study of Liu et al. (1998), the authors applied a think-aloud method to detect how Taiwanese EFL students generated notes in the process of writing in English. The findings showed that beginning EFL learners relied on their L1 to retrieve words more than advanced EFL learners did.

In another study analyzing the errors made by Taiwanese EFL college students, Chen (1998) reported that most Taiwanese students have difficulties in the use of English tenses due to the absence of verb conjugation in Mandarin. Since Mandarin is not an inflected language, Fang (1999) highlighted the teaching of English verb tenses to prevent Taiwanese EFL students from misusing English tenses due to linguistic difference.

Another grammatical error that is frequently found in Taiwanese EFL students' compositions is the misuse of English articles. Chen (2000) considered that English articles could be one of the most difficult grammatical parts for Taiwanese EFL students as there is not an equivalent syntactical device to the English article system. Master (1988) further 
indicated that beginning level EFL learners tend to be more interfered by such a linguistic difference between Mandarin and English.

Likewise, Hsin (2003 cited in Chen, 2006) scrutinized the run-on sentences in Taiwanese EFL students' writings and identified the possible causes using Error Analysis. He observed that English is a subject-prominent language, in which a subject in a sentence is always required. In contrast to subject-oriented structure, Mandarin tends to be a topiccomment language. Of course, such a linguistic difference between Mandarin and English creates learning difficulties for Taiwanese EFL learners and results in errors in their EFL writings.

In addition to the previous studies conducted in this respect, Lee's (2001) research also revealed that learners' errors are mostly resulted from L1 transfer. His study was to identify and classify errors by analyzing medical students' writing, especially their formal and informal letters. Twenty-five sophomore medical students in a class of 35 were the participants of his study. They were given six topics to write about throughout the semester. Finally, the study revealed that approximately one forth of errors $(26 \%)$ of these subjects resulted from L1 transfer. Other major errors involved in wrong words (16\%), prepositions (15\%), and articles (14\%).

Finally, Zhang (2007) shared the same concern expressed so far when stated, "it is not surprising at all that EFL learners including Chinese university students make errors in spoken and written English because language transfer or the incorporation of patterns from the native language into the target language is a common source of errors among learners of a second or foreign language" (p. 4). He also deemed it necessary to point out that English and Chinese belong to different language families. English is classified as an indo-European language; whereas, Chinese is of the Sino-Tibetan family (Fromkin\& Rodman, 1998 cited in Zhang, 2007). Therefore, the two languages have much more differences than similarities.

Among the abundance of studies done on interlingual causes, some studies have concentrated on Iranian EFL learners' errors which demonstrate the influence of Farsi as the learners' native language. For example, Koosha and Jafarpour (2006) tried to determine the extent to which Iranian EFL learners' knowledge of collocation of prepositions is affected by their L1. To this end, 200 senior English majors studying at three universities in Shahrekord served as the participants of this study. Finally, the analysis of errors of collocations indicated that Iranian EFL learners tended to carry over their L1 collocational patterns to their L2 production.

In another study, Khodabande (2007) identified and classified Iranian EFL students' chief difficulties. In doing so, 58 male and female graduate students of English were asked to take part in her research. They were given a test which included thirty Persian and thirty English headlines and were asked to translate them. All the students' translations were analyzed in order to investigate possible cross-linguistic problems in translating headlines. The results of the research indicated that the graduate students had grammatical and lexical errors in their headlines. Most local errors were caused by misuse and omission of prepositions, articles, auxiliaries, lack of subject-verb agreement, and faulty lexical choice. As a whole, the findings from the participants' translations analysis were in line with the idea that native language interference is surely the most immediately noticeable source of error (Brown, 1994) from the translation of native language to the target one.

\section{STUdies DONE ON INTRALINGUAL CAUSES}

At the outset, it was believed that most language errors were caused by the transformation from one language to another. Thus, in making decisions regarding the focus for foreign language teaching, instructors and teachers had taken into consideration errors that appear to result from the influence of their students' first language. Later, they observed evidence from language acquisition research suggesting that for some language features, "learners of different L1 backgrounds may face similar types of challenges" (Collins, 2007, p. 295). Furthermore, it was found that the influence of native language on the second language is quite minimal; that is, it affects only $3-25 \%$ of such errors (Sattayatham\&Honsa, 2007).

Richards (1971) first challenged the belief that learners' errors were the result of L1 transference. He, in his aforementioned research argued:

Many of the learners' errors came from the strategies that they use in language acquisition and the reciprocal interference of the target language items. Error Analysis would allow teachers to figure out what areas should be focused on and what kind of attention is need in an L2 classroom. So, the language teachers can be better able to develop curriculum and select materials that can facilitate L2 learning processes (p. 208).

Elsewhere, Kim (1987) identified a total of 2455 errors in the English compositions of $12^{\text {th }}$ grade Korean EFL learners. The findings showed that errors in BE and auxiliaries were the most common (419), followed by errors in prepositions (287) and that intralingual errors arose more than transfer errors.

Kim (1988) investigated errors in English verbs with reference to tense, mood, and voice. The 120 subjects were the $11^{\text {th }}$ grade Korean EFL learners who were asked to translate 42 Korean sentences into English. The results revealed that errors in mood were most frequent (903) followed by errors in voice (885) and tense (720), among the total of 2508. With regard to the sources of errors, overgeneralization (65\%) occurred the most while L1 transfer (22\%) and simplification $(13 \%)$ occurred the least.

Kim (2001) conducted another study in this respect. Indeed, the purpose of his study was to analyze errors in college students' writing samples to examine L1 interference phenomenon. He pointed out that, "it is widely believed that 
Korean learners of English often show incorrect use of English expressions due to their L1 interference" (p. 159). He continued that, "despite such a prevalent belief, the sources of learners' errors and L1 interference were not clearly identified" (p. 160). In order to examine the sources and the nature of learners' errors, he collected 30 writing samples from college freshman students who were registered for TOEIC class. Most of the learners' errors were in the areas of verbs (be $+\mathrm{V}$ for $\mathrm{V}$, be omission, -s omission, incorrect use of present perfect), prepositions (incorrect use of prepositions, redundant prepositions), articles (omission of $a$, incorrect use of $a$, omission of the, the instead of zero), plural/singular agreement, adjectives, conjunctions (incorrect use of conjunctions, stranded/redundant conjunctions). Then, errors were classified into two categories of intralingual and interlingual. Finally, the results showed that most of learners' errors were intralingual and only a few cases can be attributed to L1 interference, which lends support the assumption that L2 learners follow similar developmental patterns to those found in children's L1 acquisition. Thus, it may follow from what he found that learners' errors are not just deviant forms that should be corrected but they reflect creative process of seeking systematic rules of target language.

Moreover, Bataineh (2005) claimed, "unlike earlier Error Analyses, native language transfer is found to play a role which is at best minimal" (p. 56). Of course, his study exclusively aimed at identifying the kinds of errors Jordanian first, second, third, and fourth year university EFL students made in the use of the indefinite article. The nine types of errors were as follows:

(1) deletion of the indefinite article,

(2) writing $a$ as part of the noun/adjective following it,

(3) substitution of the indefinite for the definite article,

(4) substitution of the definite for the indefinite article,

(5) substitution of $a$ for $a n$,

(6) use of the indefinite article with unmarked plurals,

(7) use of the indefinite article with marked plurals,

(8) use of the indefinite article with uncountable nouns, and

(9) use of the indefinite article with adjectives.

Finally, the analysis revealed that all errors, except one, were independent of the learner's native language and the only type of error which could be traced back to the influence of Arabic, among other sources, was the deletion of the indefinite article.

Sattayatham and Honsa (2007), in their study, focused on Error Analysis of first year medical students from the four medical schools at Mahidol University. A total of 44\% of enrolled students participated in their study (about 237). They were asked to translate sentences from Thai into English. The data collected from the sentence-level translation were analyzed to find the most frequent errors of these medical students by using the distribution of frequency. The top-ten errors of the participants were as follows:

(1) order of adjectives,

(2) there is/are,

(3) subject-verb agreement,

(4) direct/indirect object,

(5) verbs of feeling,

(6) past tense,

(7) present perfect,

(8) reported speech,

(9) passive voice, and

(10) question tag.

Finally, the researchers concluded that the errors made by the students were both from the intralanguage and interlanguage interference. This is while the errors caused by mother tongue interference were in a small proportion.

In this respect, the next few studies deals mostly with the research done on intralingual causes of errors committed by Iranian EFL learners. Ghadessy (1980) conducted one of such studies. He also shared the same concern expressed in the overseas studies when he discussed the results of Error Analysis of 100 English compositions written by Iranian university students. The results showed that mistakes were not primarily due to inference from the native language, but to developmental errors, similar to errors made in first language acquisition.

Furthermore, Javidan (1980), in his study, tried to investigate the sources of errors made and the difficulty order followed by adult Iranian students in their learning of certain grammatical structures of English. The general difficulty order found in his study was in many ways similar to the orders reported in other L2 studies for adult ESL learners indicating that adults follow a natural and similar sequence in learning the grammatical structures of English and also that the structural difficulty order might be universal for all adults learning a second or foreign language. Three proficiency levels of students participated in his study and the results of the error analysis showed that in each proficiency group (elementary, intermediate, and advanced) the subjects' reliance on developmental strategy was greater than on the strategy of native language transfer. Furthermore, the findings of this study, while providing strong support for the claim that interference from the mother tongue is not the only source of errors adult L2 learners make, but rather a large number of errors made by these learners can be explained due to interference from the target language, indicate 
that in addition to these two major sources of errors, other factors such as teaching and testing materials and techniques, type of language exposures available to the learner, transfer from a third or more languages known by the learner, and so on, should also be evaluated as the causes of errors in L2 learning.

In another study, Tabatabai (1985) proposed that the 891 errors detected in his study were dispersed among 10 major categories such as mistakes with articles, prepositions, incorrect and confusing tenses, number, conjunctions, adjectives, subjects and predicates, verb phrases, and pronouns. The data for his research were drawn from 32 compositions written by 20 Iranian students who were in various fields of science and engineering at the States University of New York at Buffalo. He finally reported that complexity of the English language, students' incomplete knowledge or ignorance of certain structures, the interference of conversational English into written English, the transfer of training, lapses of memory, lack of sufficient practice informed writing, unfamiliarity with the requirements of written English, and pressure of communication were among the major causes of errors. As it is obvious, the causes of errors that he reported were mostly intralingual.

Likewise, Ahmadvand (2008) aimed at analyzing Iranian EFL learners' errors in their written productions. He collected the required data from different productions of some 40 learners at pre-intermediate and intermediate levels. As he reported, omissions, additions, and regularizations were among the most frequent types of errors. Moreover, based upon data, it was shown that negative transfer accounted for only $30 \%$ of all errors and most of the errors were the result of misinformation. Consequently, it was shown that negative transfer from Persian to English in written productions is neither the only source of errors, nor the major one. Indeed, Ahmadvand's (2008) results sharply decreased the role of L1 in the acquisition of English as a target language.

Hence, it follows from the reported studies in the previous part that some researchers and authorities of the field have considered intralingual causes as the common source of EFL learners' errors. Of course, quite a number of researchers have found that L2 learners at the beginning level produce a large number of interlingual errors. They also observed that as these learners progress in acquiring the norms of the target language, more and more intralingual errors are manifested (Brown, 1994 \&Littlewood, 1995 cited in Lee, 2001).

\section{CONCLUSION}

Considering reported studies makes the growing research interest in the analysis of errors more obvious. In recent years, there have been a growing number of studies in the area of Error Analysis. The underlying objections of most of these studies were to identify and classify errors and thus help teachers know the problematic areas of EFL learners at different levels of instruction in order to help students learn better. Based on the studies reviewed on EA, it is obvious that there are two opposite views toward the sources of errors committed by EFL learners. Both of these two views have been advocated by different researchers and there is enough empirical evidence for each to be true. However, Brown (1994) and Littlewood (1995) cited in Lee (2001) seem to be more comprehensive in that they believed that as learners progress in acquiring the norms of the target language, more and more intralingual errors are manifested.

In connection to the significance of second language learners' errors both in learning and teaching, TEFL educators and researchers interested in seeking the truth should re-conduct research in order to adopt appropriate teaching strategies to help EFL students learn better.

\section{REFERENCES}

[1] Ahmadvand, M. (2008).Analyzing errors of Iranian EFL learners in their written productions. Retrieved March 27, 2009, from http://moslem17.googlepapers.com/AnalysingerrorsofIranianEFLlearners.pdf

[2] Bataineh, R. F. (2005). Jordanian undergraduate EFL students' errors in the use of the indefinite article. Asian EFL Journal, 7(1),56-76.

[3] Brown, H. D. (1994). Teaching by Principles: Interactive language teaching methodology. New York: Prentice Hall Regents.

[4] Chen, H. C. (1998). A contrastive analysis of the language errors made by the Chinese students of English as a second/foreign language. Journal of Wu-Feng Applied Linguistics, 6, 224-237.

[5] Chen, H. C. (2000). Error Analysis of some features of English article usage. Journal of Wu-Feng Applied Linguistics, 8, 282296.

[6] Chen, L. L. (2006). The effect of L1 and CAI on grammar learning: An Error Analysis of Taiwanese beginning EFL learners' English essays. Asian EFL Journal, 9(2), 1-19.

[7] Collins, L. (2007). L1 differences and L2 similarities: Teaching verb tenses in English [Electronic version]. ELT Journal, 61(4), 295-304. Retrieved December $\quad 29, \quad$ from http://proquest.umi/pqdweb?did=1338974651\&sid=18\&Fmt=2\&clientld=80892\&RQT=309\&vnAME-PQD

[8] Corder, S. P. (1967).The significance of learners' errors. IRAL, 5, 161-170.

[9] Corder, S. P. (1974). Error Analysis: Perspectives on second language acquisition. London: Longman.

[10] Dulay, C., \& Burt, K. (1974).Error and strategies in child second language acquisition. TESOL Quarterly, 8, 129-138.

[11] Ellis, R. (1994). The study of second language acquisition. London: Oxford University Press.

[12] Fang, Y. C. (1999). Teaching English verb tenses to Chinese EFL students. Journal of Kuen-Shan Institute of Technology, 2 , 119-123.

[13] Fries, C. C. (1949).The Chicago Investigation. Language Learning, 2, 89-99.

[14] Ghadessy, M. (1980). Implications of Error Analysis for second/foreign language acquisition. Language Teaching, 189(2), 3104. 
[15] Hasyim, S. (2002). Error Analysis in the teaching of English. Retrieved March 27, 2009, from http://puslit2.petra.ac.id/ejournal/index.php/ing/articlePDFInterstitial/15485/15477

[16] James, C. (1998). Errors in language learning and use: Exploring Error Analysis. London: Longman.

[17] Javidan, S. (1980). Humanities Error Analysis and English language strategies of Iranian students. Unpublished doctoral dissertation, The Florida State University, U.S.

[18] Jiang, M. C. (1995). An analysis of Chinese learners' errors in prepositions. Journal of National Chiayi Institute of Agriculture, 41, 187-201.

[19] Karra, M. (2006). Second language acquisition: Learners errors and error correction in language teaching. Retrieved September 12, 2008, from http://www.proz.com/doc/633

[20] Keshavarz, M. D. (1999). Contrastive Analysis and Error Analysis (6 ${ }^{\text {th }}$ ed.).Tehran: Rahnama Press.

[21] Khodabandeh, F. (2007). Analysis of students' errors: The case of headlines. The Asian ESP Journal, 3(1), 6-21.

[22] Kim, H. (1987). An analysis of learners' errors made in their English composition especially in the high school level. Unpublished master's thesis. Chungbuk National University, Chungju, Korea.

[23] Kim, I. (1988). A study of the errors in the use of the English verbs with special reference to tense, mood, and voice. Unpublished master's thesis. BusanNational University, Busan, Korea.

[24] Kim, S. (2001). An Error Analysis of college students' writing: Is that really Konglish? Studies in Modern Grammar, 25, 159174.

[25] Koosha, M., \&Jafarpour, A. A. (2006). Data-driven Learning and Teaching collocation of prepositions: The Case of Iranian EFL Adult Learners. Asian EFL Journal, 8(8), 200-216.

[26] Lee, E. P. (2001). Error Analysis on medical students' writing. Retrieved October 21, 2008, from http://www.stc.arts.chula.ac.th/ITUA/Papers_for_ITUA_Proceedings/Eunpyo-new.pdf.

[27] Liu, C. K., Sung, C. J., \& Chien, S. C. (1998). The process of generating notes when the EFL students write English. Humanity and Society Teaching Newslettter, 8(6), 132-150.

[28] Londono Vasquez, D. A. (2007). Error Analysis. Retrieved October 21, 2008, from http://davidlondono.blogspot.com/search?updated-min=2007-01-01T00\%3A00\%3A00-08\%3A00\&updated-max=2008-01$01 \mathrm{~T} 00 \% 3 \mathrm{~A} 00 \% 3 \mathrm{~A} 00-08 \% 3 \mathrm{~A} 00 \& \mathrm{max}-$ results $=4$

[29] Master, P. (1988). Acquiring the English article system: A cross-linguistic interlanguage analysis. Paper presented at the $22^{\text {nd }}$ Annual TESOL Convention, Chicago, IL.

[30] Richards, J. C. (1971). A non-contrastive approach to Error Analysis. English Language Teaching Journal, 25, $204-219$.

[31] Richards, J. C. (1974). Error Analysis: Perspectives on second language acquisition. London: Longman.

[32] Sattayatham, A., \& Honsa, S. (2007). Medical students' most frequent errors at Mahidol University, Thailand. Asian EFL Journal,9(2), 170-194.

[33] Schachter, J., \& Celce-Murcia, M. (1977).Some reservations concerning Error Analysis. TESOL Quarterly, 11, 441-451.

[34] Tabatabai, M. (1985). Error analysis: The types and the causes of the major structural errors made by Iranian university students when writing expository and imaginative prose (Report No. AAT-8528232). New York, NY: State University of New York at Buffalo.

[35] Ying, S. Y. (1987). Types of errors in English compositions by Chinese students: A research for interlanguage. Unpublished master's thesis, Fu Jen Catholic University, Taipei, Taiwan.

[36] Zhang, S. (2007).Analysis and classifications of common errors in spoken and written English caused by Chinese university students' lack of English grammatical knowledge.US-China Foreign Language, 5(5), 1-5.

Pooneh Heydari is a lecturer at Shiraz Azad University. She is interested in L1 and L2 acquisition, syllabus design and materials development. She is a Ph.D. candidate of TEFL in IAU, Shiraz Branch. (corresponding author: Pooneh.Heydari@yahoo.com)

Mohammad S. Bagheri is an associate professor at Shiraz Azad University. He is currently the Vice Dean of I.A.U. Humanities College, Shiraz, Iran and teaches postgraduate students majoring in English Teaching. He has a number of publications and has presented a host of presentations at national and international conferences. His main areas of interest are international proficiency exams, reading strategies and use of technology. bagheries@sums.ac.ir 